\title{
Quality of Life of Patients with Post-Stroke Speech-Language Disorders
}

\author{
Yun Kyung Hwang1, Yunji Hwang ${ }^{2,3}$, Soo Ryon Kim \\ 'Division of Speech Therapy, Rehabilitation Hospital, Yonsei University Health System, Seoul, Korea \\ ${ }^{2}$ Department of Preventive Medicine, Seoul National University College of Medicine, Seoul, Korea \\ ${ }^{3}$ Cancer Research Institute, Seoul National University, Seoul, Korea \\ ${ }^{4}$ Department of Speech and Hearing Therapy, College of Health Sciences, Catholic University of Pusan, Busan, Korea
}

\section{뇌졸중 후 말-언어장애 환자의 삶의 질}

\section{황윤경 $\cdot$ 황윤지 ${ }^{2,3} \cdot$ 김수련 ${ }^{4}$}

연세의료원 재활병원 언어치료실 ${ }^{1}$, 서울대학교 의과대학 예방의학교실 ${ }^{2}$, 서울대학교 암연구소 ${ }^{3}$, 부산가톨릭대학교 보건과학대 언어청각치료학과 ${ }^{4}$

\begin{abstract}
Purpose: We examined the quality of life (QoL) in stroke patients with speech-language disorders as an aftereffect. Methods: The collected data for individuals who had been diagnosed with stroke were drawn from the Korea community health survey in 2010 and 2012. We classified them into two groups, the group with no aftereffects $(n=3,011)$ and the group with speech-language disorders $(n=367)$. Socio-demographic characteristics, medical history, and Euro QoL-5 dimensions were obtained. For statistical analysis, Analysis of Covariance and multiple linear regression analysis were conducted. Results: Age, gender, comorbidity of depression, and asthma were associated with a lower level of QoL in the speech-language disorder group. The group with speech-language disorders showed significantly lower QoL than the group with no aftereffects. Conclusion: Our findings may broaden the knowledge related to QoL for individuals with speech-language disorders. Lower QoL in speech-language disorders reconfirmed the potential importance of providing support to individuals with post-stroke speech-language disorders.
\end{abstract}

Key Words: Stroke, Communication disorder, Quality of life, Korea community health survey.

Received: August 25, 2018 / Revised: October 10, 2018 / Accepted: October 10, 2018

Correspondence: Soo Ryon Kim, Department of Speech and Hearing Therapy, College of Health Sciences, Catholic University of Pusan, 57 Oryundaero, Geumjeong-gu, Busan 46252, Korea

Tel: +82-51-510-0846 / Fax: +82-51-510-0848 / E-mail: srkim@cup.ac.kr

\section{INTRODUCTION}

사회심리적인 측면에서 의사소통 능력은 정보를 교환하는 기 능 이외에도 자아의식과 정체성을 나타내는 강력한 수단이자 삶의 질을 좌우하는 중요한 요소이다(Chapey, 2001). 국내 뇌 졸중 환자 중에는 약 $30 \%$ 가 후유증으로 말-언어 능력이 저하되 어 의사소통에 어려움을 갖고 있다(Korea Centers for Disease Control and Prevention, 2010, 2012). 전통적으로 뇌졸중 환자를 대상으로 한 연구는 정상인과 비교한 수행력 저하와 그 기능의

(cc) This is an Open Access article distributed under the terms of the Creative Commons Attribution Non-Commercial License (https://creativecommons.org/licenses/by-nc/4.0) which permits unrestricted non-commercial use, distribution, and reproduction in any medium, provided the original work is properly cited.
회복에 초점을 맞추어 왔다(Chapey, 2001; Kim, 2012). 최근에 는 뇌졸중 환자의 다양한 기능 손상으로 인한 환자의 저하된 삶의 질에 관한 관심이 고조되고 있으나, 현재까지 말-언어장애 로 특정된 기능 손상과 삶의 질과의 관계를 규명한 국내 연구는 거의 이루어지지 않았다(Brady et al., 2011; Chapey, 2001; Dickson et al., 2008; Hilari et al., 2003; Kim et al., 2012; Walshe \& Miller, 2011).

뇌졸중은 말장애와 언어장애를 유발할 수 있다. 뇌졸중으로 인한 말장애(motor disorder)에는 마비말장애(dysarthria)와 말 실행증(apraxia of speech)이 있다. 마비말장애는 말산출에 관 여하는 근육의 조절력 저하로 인하여 호흡, 발성, 조음, 공명, 속 도 및 운율 등에서 문제가 발생하고, 이로 인해 말명료도가 저 
하된 상태를 일컫는다. 말실행증이란, 말산출 시 근육이나 구 조 등의 움직임을 계획 및 프로그래밍하는 데 어려움이 있어 조음 오류, 비정상적인 운율 등을 보인다(Kim, 2012). 이러한 증상은 뇌졸중 환자에게 단독 혹은 복합적으로 나타날 수 있 으며 만성적인 의사소통장애 후유증을 남기기도 한다(Brady et al., 2011; Chapey, 2001). 한편, 대표적인 언어장애인 실어증 (aphasia)은 말하기, 듣기, 읽기, 쓰기의 언어 영역 전반에 걸쳐 정상인에 비해 저하된 언어 수행력을 보인다(Kim, 2012). 뇌졸 중 후 실어증 환자의 언어 수행력은 이름대기, 따라말하기, 문 장 산출, 담화 산출 등의 '말하기' 과제와 단어 듣고 가리키기, 질문에 '예/아니오로 답하기, 듣고 지시 따르기 등의 ‘듣기' 과제 및 소리 내어 읽기, 읽고 지시 따르기 등의 '읽기' 과제, 베껴쓰 기, 받아쓰기 등의 '쓰기' 과제 등을 실시하여 평가된다(Kim et al., 2008). 본 연구에서는 기술상 편의를 위해 앞서 언급한 말장 애와 언어장애를 통칭하여 '말-언어장애'로 정의하기로 한다.

기능적 손상에 주목하는 기존의 접근은 말-언어장애 환자 의 실제 심리 및 사회적 삶에 미치는 영향을 충분히 설명해 주 지 못한다는 견해가 있다(Chapey, 2001; Dickson et al., 2008). 기능적 손상 접근법의 제한점을 보완하고자 최근에는 뇌졸중 후 말-언어장애가 실제 개인의 삶의 질에 미치는 영향에 대한 관심이 높아지고 있다. 선행 연구에 따르면, 뇌졸중 후 다양한 말-언어장애는 공통적으로 사회적 고립 및 낙인, 사회 관계적 참 여 활동의 제약, 자존감의 저하, 부정적 감정 상태 등을 초래하여 삶의 질을 저하시킨다(Brady et al., 2011; Chapey, 2001; Dickson et al., 2008; Hilari et al., 2003; Walshe \& Miller, 2011). 최근에 는 국내에서도 '실어증 환자의 삶의 질 측정 도구(stroke and aphasia quality of life scale-39)' (Kim et al., 2012)가 개발 및 번역되어 삶의 질 측면을 고려한 언어 중재 및 관리를 위한 노력 이 진행 중이다(Kim et al., 2012; Manders et al., 2010; Williams et al., 1999).

말-언어에 어려움이 있는 경우 그렇지 않은 개인에 비해 삶 의 질이 저하된다는 의견은 대체로 일치하지만, 저하된 삶의 질 에 영향을 미치는 요인에 관해서는 일치된 결론을 도출하기에 부족하다. 실어증 환자를 대상으로 실시한 연구에서 실어증 중 증도, 기능적 활동 수준, 우울증은 일관적으로 삶의 질에 부정 적인 영향을 미치는 것으로 알려져 있다(Hilari et al., 2012). 또 한 청각 및 시각 능력이 저하되면 의사소통 능력이 감소된다. 중 증도가 심한 경우에는 숙련된 대화 상대자와의 의사소통만 제 한적으로 가능하다(Erber \& Scherer, 1999). 천식 환자의 경우 에는 발성에 필요한 호흡량 부족 등의 문제로 말산출이 부자연 스러운 특징을 보였다(Lee et al., 1988). Erber \& Scherer(1999) 는 동반 질병으로 인한 반복적인 의사 전달의 실패는 당사자의 대인관계와 사회심리적 웰빙에 심각한 영향을 미친다고 언급하
였다. 반면, 인구학적 특성(연령, 성별, 교육 수준, 직업 유무), 뇌 졸중 종류 및 발병 시기, 인지 및 언어적 기능 등에 관한 요인 은 아직 연구가 부족하거나 일반화하기에는 상반된 연구가 혼 재한다(Hilari et al., 2012).

본 연구에서는 국내 전국의 지역사회 거주자를 대상으로 수 집된 지역사회건강조사 자료를 기반으로 뇌졸중 후 말-언어장 애 유무에 따라 삶의 질 점수에 차이가 있는지 확인하고자 한 다. 또한 말-언어장애 환자의 삶의 질에 영향을 미치는 요인을 살펴봄으로써 이들의 삶의 질 개선을 위한 통합적인 이해와 지 원 프로그램에 대한 필요성을 제안하고자 한다.

\section{MATERIALS AND METHODS}

\section{연구 대상}

본 연구는 2010년 및 2012년에 조사된 지역사회건강조사 원 시자료를 사용 허가를 받아 이용하였다. 본 자료는 전국에 거주 하는 만 19세 이상을 대상으로 표본으로 선정된 가구에 직접 방 문하여 1:1 면접 설문조사를 통해 작성되었다. 본 연구에 사용된 설문 조사는 질병관리본부 생명윤리 위원회의 승인(201002CON-22-P, 2012-07CON-01-2C)을 받아 2010년 8월 16일 2010년 10월 31일(약 3개월) 및 2012년 8월 16일 2012년 10월 31일(약 3개월)로 총 약 6개월에 걸쳐 진행되었다(Korea Centers for Disease Control and Prevention, 2010, 2012).

본 연구에서는 뇌졸중 후 후유장애 종류에 관한 설문을 포 함하는 최근 자료인 2010년 및 2012년 지역사회건강조사 자료 중 뇌졸중으로 진단받은 적이 있다고 응답한 9,079 명의 데이터 를 추출하였다. 이 중 뇌졸중으로 인해 현재 기능장애로 인한 불편함을 느끼는 특별한 후유증이 없었거나 혹은 과거에는 있 었으나 현재에는 회복되었다고 응답한 인원을 제외한 5,022 명 을 추출하였다. 구체적으로 살펴보면, 뇌졸중으로 인한 후유증 이 없다고 응답한 인원은 4,621명이었고, 뇌졸중 후 후유증으로 말-언어장애만을 겪고 있다고 응답한 인원은 401명이었다. 마지 막으로 결측치가 없어 본 연구의 분석에 포함한 대상자 3,378 명 을 최종 분석 대상자로 하였다. 연구 분석을 위하여 후유증이 없는 집단 $(\mathrm{n}=3,011)$ 과 말-언어장애 집단 $(\mathrm{n}=367)$ 으로 구분 하였다. 최종 분석에 포함된 두 집단의 대상자 수 비율은 뇌졸 중 후 언어장애와 말장애의 유병률이 약 $10 \%$ 라는 연구 결과와 유사하였다(Flowers et al., 2013). 또한 유의수준 0.05 수준에 서 효과크기 0.25 를 검정할 수 있는 대상자 수를 만족하였다 (Cohen, 1992).

\section{분석 변수}

대상자의 사회인구학적 특성을 살펴보기 위하여, 연령, 성별, 
교육 수준, 연평균 소득 수준, 독거 여부 문항을 사용하였다. 대 상자의 교육 수준은 무학, 초등학교 졸업 이하(1 6년), 고등학 교 졸업 이하(7 9년), 대학교 재학 이상(10년 이상)으로 구분하 였고, 연평균 소득 수준은 총 대상자의 소득 4분위를 기준으로 구간을 설정하였다. 교육 수준과 연평균 소득 구간 설정 기준 은 삶의 질 관련 선행 연구를 참조하였다(Chung \& Joung, 2010; Kim, 2016; Lee, 2014).

설문조사 중 뇌졸중 진단 여부, 후유증 상태, 후유증 종류, 우울증 진단 여부, 천식 진단 여부, 백내장 진단 여부 자료를 분 석하여 의료 관련 특성을 조사하였다. 뇌졸중으로 인한 후유 증 상태는 뇌졸중으로 의사에게 진단을 받았다고 보고한 응답 자가 ‘후유증을 앓고 있다, ‘후유증이 있었지만 지금은 회복되 었다, '특별한 후유증이 없었다' 중에서 선택하였다. 후유증 종 류는 해당 대상자가 과거 또는 현재에 '한쪽 팔 또는 다리 마 비', '안면 마비', '발음이 잘 안되는 등의 의사소통장애', '삼키거 나 먹는 것의 장애', '눈이 잘 안 보임' 중에서 해당되는 항목을 선택하여 조사되었으며, 복수 응답이 가능하였다.

설문의 항목은 임상가가 아닌 일반인을 대상으로 제시되었 기에, 연구 목적을 위해 말-언어 측면과 관련된 문항에 관하여 좀 더 명확한 정의가 필요하겠다. 임상적 경험에 의하면 일반인 의 경우 말과 언어를 대개 명확하게 구분하지 않으며 착어나 막힘, 말더듬 등 언어적 측면의 손상에 의한 증상도 '발음이 잘 되지 않는다고 호소하는 경우가 많다. 따라서 설문 형식으로 진행된 본 연구 내에서는 '발음이 잘 안되는 등의 의사소통장 애' 항목을 '말이나 언어, 또는 말과 언어 측면 모두에 어려움을 겪는 포괄적 의미의 말-언어장애’라고 규정하였다.

설문 문항에 포함된 다양한 질환(고혈압, 당뇨병, 고지혈증, 심근경색증, 협심증, 관절염, 골다공증, 폐결핵, 천식, 알레르기 비염, 아토피 피부염, 백내장, B형 간염, 우울증, 대사증후군, 에 이즈)의 유무와 만성 질병의 개수는 성인의 삶의 질에 부정적인 영향을 미치는 것으로 알려져 있다(Kim et al., 2017). Cohen et al.(2013)의 제안에 따라, 설문 질환 중 독립변수에 해당하는 말-언어 기능 저하와 연관이 있는 질환으로 알려져 있는 우울 증, 천식, 백내장(Erber \& Scherer, 1999; Lee et al., 1988)을 변 수로 선정하였다. 만성 질병의 개수를 변인으로 추가하는 경우 우울증 및 백내장 변수와의 상관관계가 높아 다중공선성이 발 생하였다. 삶의 질에 영향을 미치는 개별 요소를 조사하기 위한 연구 목적을 위하여 질병 개수를 변인에서 제외하고 개별 질병 만을 변인으로 채택하였다.

건강 관련 삶의 질 측정도구인 '한국판 EuroQoL-5 dimensions (EQ-5D) (Nam et al., 2007)' 문항에 응답한 자료를 토대 로 하였다. $\mathrm{EQ}-5 \mathrm{D}$ 는 운동 능력, 자기 관리, 일상 활동, 통증/불 편, 불안/우울의 다섯 가지 측면에서 '전혀 문제가 없다'(level
1), '다소 문제가 있다'(level 2), '매우 문제가 있다'(level 3)의 세 단계 척도에 응답하도록 구성되어 있다. 본 자료는 질병관리본 부(Nam et al., 2007)에서 제시한 가중치에 따라 삶의 질 점수 로 환산되었다. 삶의 질 점수는 모든 측면에서 level 1 로 응답한 경우인 최대 1점부터, 모든 문항에서 level 3으로 응답한 경우인 최소 -0.171 의 분포를 갖는다. 질병관리본부에서 제시한 한국 형 건강 관련 삶의 질 가중치를 이용하였다(Nam et al., 2007).

\section{통계 분석}

수집된 자료는 통계분석 프로그램인 SPSS (ver. 18, SPSS Inc., Chicago, IL, USA)를 이용하여 분석하였다. 관련 변인을 고려 하여 보정된 두 집단의 삶의 질 점수를 비교하기 위하여 공분 산분석을 시행하였다. 또한, 뇌졸중 후 말-언어장애가 삶의 질 에 미치는 영향 및 영향 요인을 알아보기 위하여 회귀분석을 시행하였다. 이 중 일부 독립 변인이 범주형 범주를 포함하므로 가변수 회귀분석으로 분석하였다. '질병과 삶의 질' 주제의 선행 논문에서 표본의 대표성을 위하여 전체 인구를 대표할 수 있도 록 가중치를 적용하지 않은 기존의 연구 방법을 참고하여 본 연 구의 통계 분석 방법의 적절성을 확인하였다(Hilari et al., 2003; Kim et al., 2015; Park \& Yim, 2014).

\section{RESULTS}

\section{대상자 특성}

대상자의 일반적 특성을 Table 1에 제시하였다. 말-언어장애 집단의 평균 연령은 70.32세(표준편차 \pm 9.10 )로, 후유증이 없 는 집단의 평균 연령 68.96세(표준편차 \pm 9.94)에 비해 유의하 게 높았다 $(p=0.008)$. 또한 말-언어장애 집단은 후유증이 없 는 집단에 비해 통계적으로 유의하게 남성의 성비가 높았으며 ( $p=0.003)$, 독거를 하고 있는 비율은 낮았다 $(p=0.040)$. 교육 수준, 연평균 소득 수준, 우울증, 천식, 백내장 진단 여부의 비율 은 두 집단 간 유의한 차이가 없었다.

\section{뇌졸중 후 말-언어장애 여부에 따른 삶의 질 점수 차이}

뇌졸중을 경험하였지만 현재 후유증이 없는 집단과 말-언어 장애의 후유증을 않고 있는 집단 두 집단의 삶의 질 점수에 차 이가 있는지 알아보았다. 관련 변인(연령, 성별, 교육 수준, 연평 균 소득 수준, 독거 여부, 우울증 여부, 천식 여부, 백내장 여부) 을 고려하지 않은 두 집단의 삶의 질 평균 점수는 뇌졸중 후 말-언어장애가 있는 집단의 삶의 질 점수가 평균 0.812 점(표준 편차 \pm 0.214 ), 후유증이 없는 집단의 점수는 0.878점(표준편차 $\pm 0.157)$ 으로 조사되었다. Analysis of Covariance 분석을 이 용하여 관련 변수를 통제한 후 보정된 두 집단의 삶의 질 추정 
평균 점수는 말-언어장애 집단이 0.814점(표준오차 \pm 0.008 ), 후유증 없는 집단이 0.877점(표준오차 \pm 0.003$)$ 으로 말-언어 장애 집단은 후유증이 없는 집단에 비해 삶의 질 점수가 유의 하게 낮았다(Table 2).

\section{뇌졸중 후 말-언어장애 집단의 삶의 질에 영향을 미치는 요인}

첫째, 현재 뇌졸중 후유증이 없는 집단의 삶의 질에 영향을 미치는 특성을 알아보았다. 연령, 성별, 교육 수준, 연평균 소득 수준, 독거 여부가 후유증이 없는 집단의 삶의 질 점수에 미치 는 영향을 파악하기 위한 다중회기분석을 시행한 결과는 Table

Table 1. General characteristics of study subjects

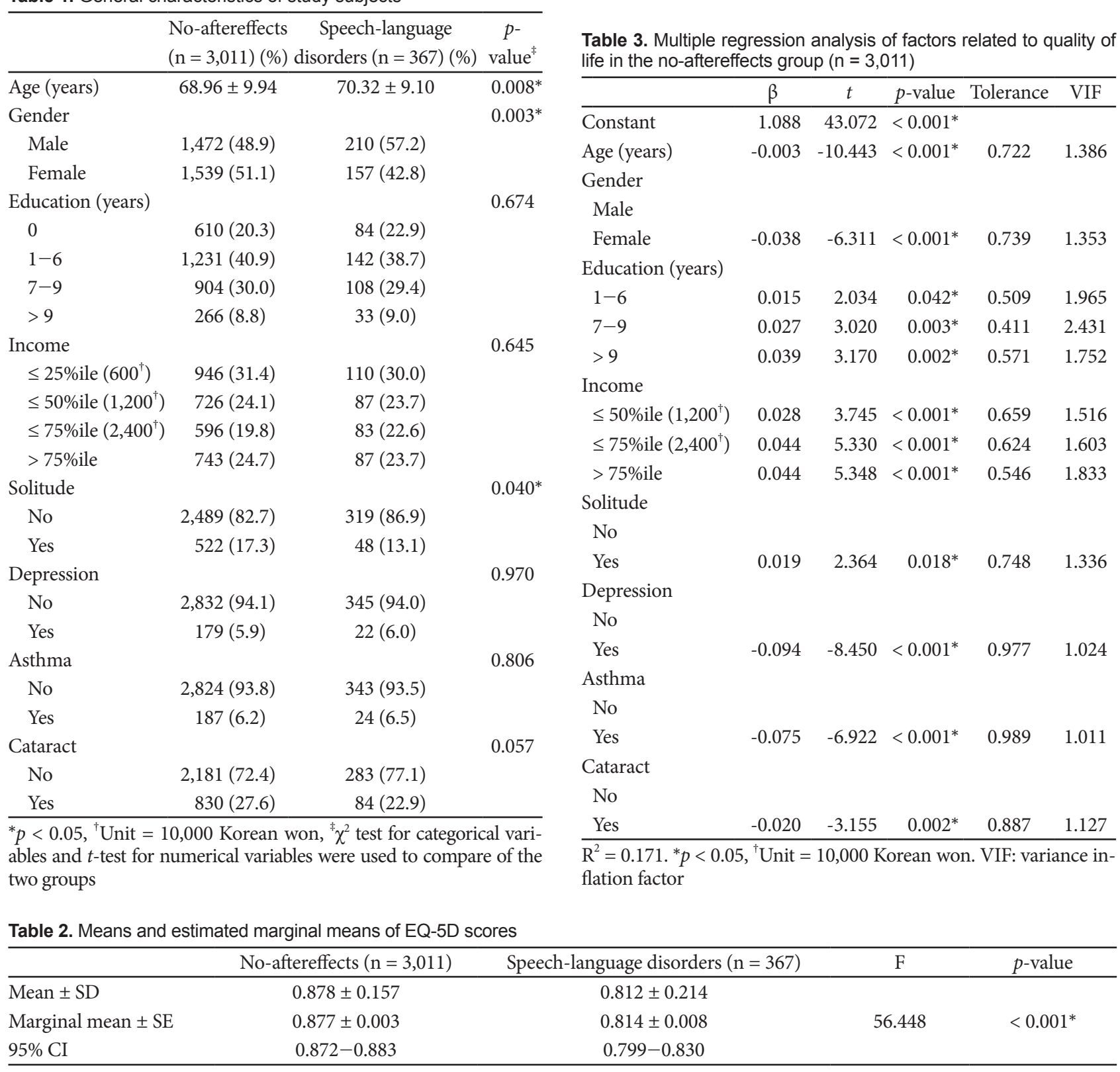

Scores were adjusted for age, gender, education, income, solitude, depression, asthma, cataract. ${ }^{*} p<0.05$. EQ-5D: Euro QoL-5 dimensions, QoL: quality of life, SD: standard deviation, SE: standard error, CI: confidence interval
3 과 같다. 회귀모형은 $\mathrm{F}$ 값이 51.652 , 유의수준 $p<0.001$ 로 유 의하였으며, 본 회귀모형에 의해 삶의 질 점수가 $17.1 \%$ 설명되는 것으로 나타났다. 변인들 간 다중공선성 문제가 없음[공차한계 0.1 이상, variance inflation factor (VIF) 값 10 미만]을 확인한 후 다중회귀분석을 실시한 결과, 후유증이 없는 집단에서 삶의 질 점수는 연령이 1 세 증가할수록 0.003 점 $(p<0.001)$, 남성보다 여성이 0.038점 $(p<0.001)$, 우울증이 있는 경우 0.094점 $(p<$ $0.001)$, 천식이 있는 경우 0.075 점 $(p<0.001)$, 백내장을 동반하 는 경우 0.020 점 $(p=0.002)$ 하락하여 부정적인 영향을 미쳤다. 반면, 교육 수준이 높을수록, 연평균 소득이 높을수록, 독거를 하는 경우에 삶의 질에 긍정적인 영향을 미치는 것으로 나타났 life in the no-aftereffects group $(n=3,011)$

Male

Education (years)

$1-6$

$\begin{array}{lllll}0.027 & 3.020 & 0.003^{*} & 0.411 & 2.431\end{array}$

$>$

$\leq 75 \%$ ile $\left(2,400^{\dagger}\right)$

Solitude

Yes

Depression

Yes

011

No

$\mathrm{R}^{2}=0.171 .{ }^{*} p<0.05,{ }^{\dagger}$ Unit $=10,000$ Korean won. VIF: variance inflation factor
Table 2. Means and estimated marginal means of EQ-5D scores 
다(Table 3).

둘째, 말-언어장애 집단을 대상으로 동일한 변인의 다중회귀 분석을 시행하였다. 본 회귀분석 역시 다중공선성 문제가 없음 을 확인하였다(공차한계 0.1 이상, VIF 값 10 미만). 동일한 변인 들이 말-언어장애 집단의 삶의 질 점수에 미치는 영향을 살펴 본 회귀모형은 $\mathrm{F}$ 값이 6.825 , 유의수준 $p<0.001$ 로 유의하였 다. 본 회귀모형을 말-언어장애 집단의 삶의 질 점수를 $18.8 \%$ 설명하는 것으로 나타났다. $\mathrm{EQ}-5 \mathrm{D}$ 점수는 연령이 증가할수록 0.007 점이 낮아지고 $(p<0.001)$, 여성이 남성에 비해 0.054점이 낮았다 $(p=0.026)$. 연평균 소득 수준과 관련하여, '25 퍼센타일 이하(600만 원 이하)' 집단이 '50 퍼센타일 이하(1,200만 원 이하)' ( $\beta=0.066, p=0.026)$, '75 퍼센타일 이하(2,400만 원 이하)' $(\beta=$ $0.080, p=0.012$ 집단에 비해 $\mathrm{EQ}-5 \mathrm{D}$ 점수가 낮았으나, 75 퍼 센타일 이상 고소득 구간과는 유의한 차이를 보이지 않았다. 동 반 질병 측면에서는 우울증 $(\beta=-0.102, p=0.026)$, 천식 $(\beta=$ $-0.094, p=0.026)$ 이 있는 집단이 없는 집단에 비해 $\mathrm{EQ}-5 \mathrm{D}$ 점 수가 유의하게 낮았다. 교육 수준, 독거 여부, 백내장 여부는 EQ$5 \mathrm{D}$ 점수에 통계적으로 유의한 영향을 미치지 않았다(Table 4).

Table 4. Multiple regression analysis of factors related to quality of life in post-stroke speech-language disorders $(n=367)$

\begin{tabular}{|c|c|c|c|c|c|}
\hline & $\beta$ & $t$ & $p$-value & Tolerance & VIF \\
\hline Constant & 1.307 & 12.541 & $<0.001^{*}$ & & \\
\hline Age (years) & -0.007 & -5.489 & $<0.001^{*}$ & 0.739 & 1.353 \\
\hline \multicolumn{6}{|l|}{ Gender } \\
\hline \multicolumn{6}{|l|}{ Male } \\
\hline Female & -0.054 & -2.231 & $0.026^{*}$ & 0.742 & 1.347 \\
\hline \multicolumn{6}{|l|}{ Education (years) } \\
\hline $1-6$ & -0.034 & -1.158 & 0.247 & 0.527 & 1.898 \\
\hline $7-9$ & -0.004 & -0.131 & 0.896 & 0.450 & 2.224 \\
\hline$>9$ & 0.039 & 0.852 & 0.395 & 0.619 & 1.615 \\
\hline \multicolumn{6}{|l|}{ Income } \\
\hline$\leq 50 \%$ ile $\left(1,200^{\dagger}\right)$ & 0.066 & 2.241 & $0.026^{*}$ & 0.662 & 1.510 \\
\hline$\leq 75 \%$ ile $\left(2,400^{\dagger}\right)$ & 0.080 & 2.526 & $0.012^{*}$ & 0.590 & 1.694 \\
\hline$>75 \%$ ile & 0.048 & 1.503 & 0.134 & 0.574 & 1.741 \\
\hline \multicolumn{6}{|l|}{ Solitude } \\
\hline \multicolumn{6}{|l|}{ No } \\
\hline Yes & 0.032 & 0.935 & 0.350 & 0.771 & 1.297 \\
\hline \multicolumn{6}{|l|}{ Depression } \\
\hline \multicolumn{6}{|l|}{ No } \\
\hline Yes & -0.102 & -2.238 & $0.026^{*}$ & 0.893 & 1.120 \\
\hline \multicolumn{6}{|l|}{ Asthma } \\
\hline \multicolumn{6}{|l|}{ No } \\
\hline Yes & -0.094 & -2.240 & $0.026^{*}$ & 0.966 & 1.035 \\
\hline $\begin{array}{l}\text { Cataract } \\
\text { No }\end{array}$ & \multicolumn{4}{|c|}{ Cataract } & \\
\hline Yes & 0.027 & 1.037 & 0.300 & 0.876 & 1.141 \\
\hline
\end{tabular}

$\mathrm{R}^{2}=0.188 .{ }^{*} p<0.05,{ }^{\dagger}$ Unit $=10,000$ Korean won. VIF: variance inflation factor

\section{DISCUSSIONS}

재활 치료 및 관리의 궁극적인 목표는 환자의 삶을 질을 최 대한 회복시키고 사회관계 활동에 참여하도록 촉진하는 것이 다. 그러나 실제 임상 현장에서는 환자의 삶의 질 개선을 직접 적인 목표로 설정하기보다는 손상된 기능의 회복을 중재 목표 로 계획하는 것이 더 일반적이다. 손상된 말-언어 수행력의 회 복을 목표로 하는 언어재활 임상 현장에서는 환자의 사회심리 적 문제가 간과되기 쉽다. 혹은 심리적인 문제를 말-언어장애에 따른 자연스러운 현상이라고 받아들이는 경우가 있다(Chapey, 2001).

본 연구는 뇌졸중 후 말-언어장애 후유증을 겪는 개인의 저 하된 삶의 질에 관한 관심을 고취하고, 말-언어장애 환자의 삶 의 질 개선을 위해 기능 손상의 회복에 관한 접근뿐만 아니라 사회심리적 측면의 통합적인 이해와 지원의 필요성을 조명하였 다는 데 의의가 있다. 본 연구에서 뇌졸중 후 말-언어장애는 삶 의 질을 유의하게 저하시키는 것으로 나타났다. 이는 뇌졸중 후 말-언어장애가 기능적 손상에 그치는 것이 아니라 삶의 질을 저하시킨다는 선행 연구와 일치한다. 선행 연구에 따르면, 뇌졸 중으로 인한 실어증 환자들은 정상 노년층과 뇌졸중 후 후유 장애가 없는 개인에 비해 대인관계, 삶의 활동과 참여에 제약을 경험하며, 그로 인해 전반적인 삶의 질이 상당히 저하되어 있다 (Chapey, 2001; Dickson et al., 2008; Kim et al., 2015; Ross \& Wertz, 2002, 2003; Walshe \& Miller, 2011).

뇌졸중 후 현재 후유증이 없는 개인의 삶의 질에 부정적인 영향을 미치는 요소로는 고연령, 성별(여성), 우울증, 천식, 백내 장이었으며, 긍정적인 영향 요소로는 고학력, 고소득, 독거 상 태가 있었다. 반면, 뇌졸중 후 말-언어장애가 있는 개인의 삶에 부정적인 영향을 미치는 요소에는 고연령, 성별(여성), 우울증, 천식이 있었다. 일반적으로 고연령, 여성, 우울증, 천식은 정상 노년층의 삶의 질을 저하시키는 요인으로 알려져 있다(Edelen et al., 2014; Joe et al., 2016; Kim, 2009; Lee, 2014). 이 요인들 은 뇌졸중 혹은 말-언어장애가 있는 개인의 삶의 질에도 부정 적인 영향을 보여 우리나라 노년층의 삶의 질 영향 요인의 일반 적 특징을 일부 공유하는 결과를 나타냈다. 반면, 정상 노년층 의 삶의 질에 긍정적인 영향을 미치는 것으로 알려진 고학력, 비 독거 상태, 고소득(Joe et al., 2016; Kim, 2009; Lee 2014) 요인 은 본 연구에서 일부 상이한 결과를 나타냈다.

일반적으로 정상 노년층에서 비독거 개인에 비해 독거 개인 이 더 낮은 삶의 질을 보인다는 선행 연구(Kim et al., 2008)와 달리, 본 연구에서 뇌졸중을 경험한 개인의 경우 독거 상태의 개인이 비독거 개인보다 오히려 삶의 질이 높은 경향을 보였다. 정상 노년층에서의 독거노인은 부양가족이 없어 동거 노인 가 
구에 비해 건강 상태 저하, 사회경제적 지위의 저하, 사회심리적 고립을 경험하는 것으로 보고된다(Lee, 2004). 반면, 뇌졸중 후 말-언어장애 환자는 동거 여부와 관계없이 가족과의 연락 빈도 가 병전과 비교하여 대부분 유지되거나 증가하는 양상을 보였 다. 한편, 친구와의 연락 빈도 및 관계 크기(network size)는 병 전과 비교하여 크게 감소하는 것으로 나타났는데, 가족관계를 넘어 사회적 수준의 관계망과 참여의 감소가 말-언어장애 환자 의 삶의 질 저하와 밀접한 영향을 보였다(Hilari \& Northcott, 2006). 따라서 일반 독거노인과는 대조적으로 뇌졸중 후 말-언 어장애 환자는 가족과의 동거 여부가 고립감이나 우울감에 크 게 영향을 미치지 않는 것으로 추측할 수 있다. 또한 말-언어장 애 환자 중 병전에 비해 가족과의 연락 빈도가 증가했다고 답 변한 집단이 병전과 연락 빈도가 비슷하다고 응답한 집단에 비 해 더욱 낮은 삶의 질 점수를 나타냈다는 연구 보고가 있다 (Hilari \& Northcott, 2006). 병전에 비해 가족과의 연락 빈도가 증가했거나 동거를 하는 경우, 뇌졸중 중증도에 따라 개인에게 추가적인 도움이 필요하거나 일상생활 수행 능력이 저하된 상 황에 기인한 현상일 가능성을 배제할 수 없다. 이러한 원인으로 정상 노년층에서 독거노인이 비독거노인에 비해 저하된 삶의 질 을 보인다는 선행 연구와 상이한 결과를 보였을 것으로 추측할 수 있으며, 독거 여부와 삶의 질 간의 관계에 관한 정확한 파악 을 위해서는 추후 뇌졸중의 중증도, 일상생활 수행능력 등 추 가적인 요소를 고려하는 것이 도움이 될 것으로 사료된다.

학력의 경우, 후유증이 없는 집단에서는 학력이 높을수록 삶의 질이 증가하는 양상으로 정상 노년층의 연구와 일치하였 다(Joe et al., 2016; Kim, 2009; Lee 2014). 반면, 말-언어장애 환자는 일정 소득 구간까지만 삶의 질이 증가하고 이후에는 소 득의 증가가 삶의 질에 유의한 영향을 미치지 않았다. 이와 유 사하게 후유증이 없는 집단에서는 교육 수준이 높을수록 삶의 질이 증가하여 정상 노년층의 연구 결과와 유사했으나, 말-언어 장애 환자는 교육 수준과 삶의 질 간에 유의한 상관관계를 보이 지 않았다. 정상 노년층의 삶의 질에 중요한 영향을 미치는 요소 로 알려진 학력과 소득 수준은 자기 효능감과 관련이 있다. 즉, 학력이 높고 소득 수준이 높은 개인일수록 대체로 자기 효능감 을 높게 평가하며 이는 주관적인 삶의 질에 긍정적인 영향을 준 다(Bae \& Park, 2009). 그러나 말-언어장애 환자의 사회적 고립 및 낙인, 사회 관계적 참여 활동의 제약이 자기 효능감을 감소시 킨다(Brady et al., 2011; Chapey, 2001; Dickson et al., 2008; Hilari et al., 2003; Walshe \& Miller, 2011). 정상 노년층을 대상 으로 한 선행 연구 및 본 연구에서 뇌졸중 후 후유증이 없는 집단에서의 결과와는 다르게, 말-언어장애 환자의 경우에는 상 위 학력과 소득 구간에서 삶의 질과 일관적인 양의 선형 상관관 계를 보이지 않았다. 이는 말-언어장애로 인한 자기 효능감의
저하가 고학력이나 고소득으로 인한 자기 효능감 증가 효과를 상쇄하였을 가능성이 있다.

동반 질병 측면에서는 뇌졸중 후 후유증이 없는 개인은 천식 과 백내장 모두 삶의 질에 부정적인 영향을 미쳤다. 반면, 말언어장애 개인은 천식이 있는 경우에만 유의하게 부정적인 영 향을 나타냈다. 본 연구에서 조사한 동반 질병 중 천식과 백내 장은 공통적으로 의사소통 기능 저하에 영향을 미칠 가능성이 있는 것으로 알려져 있다(Erber \& Scherer, 1999; Heine \& Browning, 2002; Lee et al., 1988). 천식 환자는 한 호흡에 산 출하는 음절의 수가 적고, 발화 단위 간 심이 길었다. 또한 대화 시간 중 많은 시간을 호흡 조절에 할애해야 하는 등 말산출 측 면의 어려움이 두드러졌다(Lee et al., 1988). 한편, 백내장 등의 시각장애는 활자 읽기를 하는 데 어려움을 겪고, 입 모양, 표정, 제스처 등 시각 단서가 제한되어 상대방의 말을 청각적으로 이 해하는 데 어려움을 보이는 등 이해 언어 측면의 문제를 초래할 수 있다(Erber \& Scherer, 1999; Heine \& Browning, 2002). 동 반 질병과 언어 기능 측면의 관련성을 고려한다면, 뇌졸중 후 후유증이 없는 개인은 말-언어의 이해 및 산출 기능 저하에 민 감하게 영향을 받는 반면에 뇌졸중 후 말-언어장애가 있는 개 인의 삶의 질은 이해 언어보다는 말산출 기능의 저하에 더욱 민감하게 작용한다는 가능성이 제기된다. 그러나 본 연구에서 는 대상자가 말산출 측면에 어려움을 보이는 집단과 언어 측면 에 어려움을 보이는 집단이 구분되지 않았고, 관련된 인지 능 력 및 말-언어장애의 중증도가 자세히 조사되지 않은 한계가 있다. 따라서 삶의 질에 말산출과 언어 측면의 문제가 미치는 독립적인 영향을 밝히기 위해서는 추후 심층적인 연구가 필요 하다. 또한 말-언어 측면 이외의 질병의 특징이 삶의 질에 미치 는 영향에 관한 충분한 고찰이 함께 이루어져야 하겠다.

한편, 언어 수행력의 손상 정도와 삶의 질의 관계에 관한 연 구는 아직 합의가 이루어지지 않고 있다. 여러 연구에서 실어증 중증도가 높을수록, 즉 언어 능력 손상의 정도가 심할수록 더 욱 낮은 삶의 질을 나타냈다(Cruice et al., 2003; Hilari et al., 2003). 반면, 기존의 표준화된 언어 평가 도구의 점수가 직접적 으로 삶의 질에 유의한 영향을 미치지는 않는다는 상반된 결과 도 보고되었다(Ross \& Wertz, 2002). Ross \& Wertz(2002)는 전 통적 언어 중재 접근을 통해서는 실어증 환자의 삶의 질을 직접 적으로 향상시키기에는 한계가 있다는 주장을 제기하였다. 임 상에서 뇌졸중 후 말과 언어장애를 겪는 개인의 삶의 질 향상 을 위해서는 중재를 계획할 때 환자의 기능 손상에 대한 회복 적 접근과 본 연구에서 살펴본 개인적 요소 이외에도 다양한 상황 맥락에서의 효율적인 의사소통 능력 증진과 사회 참여를 촉진하는 목표를 함께 추구해야 할 것이다.

이들의 저하된 삶의 질에는 자립 수준, 사회적 관계, 정서심 
리 상태, 개인 및 사회적 환경 등 다양한 요소가 영향을 미치며 (Hilari et al., 2003; Ross \& Wertz, 2003), 뇌졸중 환자의 손상 특성에 대한 풍부한 지식을 바탕으로 환자 및 보호자 교육이 중요하다(Back \& Jun, 2012). 본 연구는 전국의 지역사회 거주 자를 대상으로 뇌졸중 후유증으로 인한 말-언어장애가 개인의 삶의 질에 부정적인 영향을 미친다는 것을 재확인하고, 뇌졸중 후 말-언어장애를 겪는 개인의 저하된 삶의 질과 관련된 요소 를 파악하였다. 그러나 본 연구 결과에서 나타난 말-언어장애 가 개인의 삶의 질에 영향을 미치는 요인은 대부분 성별, 질병 등 개인이 예방하거나 조절하기 어려운 요인이 많았다. 이는 뇌 졸중 후 말산출과 언어 측면에 어려움을 겪는 개인에게 개인적 요소 및 기능 손상의 회복에 관한 접근뿐만 아니라 사회심리적 측면의 통합적인 이해와 지원이 필요하다는 것을 시사한다. 현 재 대부분의 언어 중재는 기능적 손상의 회복을 목표로 한다. 본 연구는 전국 단위의 대규모 설문을 통해 뇌졸중 후 말-언어 측면의 기능적 손상 측면뿐만 아니라 환자의 저하된 삶의 질에 관한 관심을 고취하고, 환자의 삶의 질에 대한 이해와 개선을 위한 상담 프로그램의 중요성을 재확인하였다는 데 의의가 있 다. 그러나 본 연구는 언어장애 전문가가 아닌 일반인을 대상으 로 설문한 2차 자료를 이용한 분석이므로 응답자가 호소하는 의사소통의 문제를 말장애와 언어장애로 세분화하지 못하였다. 또한 응답자의 관련 인지 능력 및 말-언어장애 중증도를 파악 하지 못하였다는 제한점이 있다. 추후 말장애와 언어장애를 세 분화하고 중증도를 고려하여 통합적인 삶의 질 영향 요인을 살 펴보는 연구가 이루어진다면, 임상에서 개별화된 환자 중재 및 상담에 더욱 유용한 정보를 제공할 수 있을 것이라 기대한다.

중심 단어 : 뇌졸중·언어장애·삶의 질·한국 지역사회건강조사.

\section{Ethical Statement}

The study was approved by the Institutional Review Board of Korean Centers for Disease Control and Prevention (\#2010-02CON-22-P, \#201207CON-01-2C).

\section{Acknowledgments}

The authors thank the participants.

\section{Declaration of Conflicting Interests}

There are no conflict interests.

\section{Funding}

NA

\section{REFERENCES}

Back, J. Y. \& Jun, S. E. (2012). Effects of symptom-based discharge education for stroke patients. Journal of the Korean Data Analysis Society, 14(5), 2541-2553.

Bae, N. R. \& Park, C. S. (2009). A study on the ecological factors affecting the quality of life among the elderly people. Journal of the Korean $\mathrm{Ge}$ rontological Society, 29(2), 761-779.
Brady, M. C., Clark, A. M., Dickson, S., Paton, G., \& Barbour, R. S. (2011). The impact of stroke-related dysarthria on social participation and implications for rehabilitation. Disability and Rehabilitation, 33(3), 178-186.

Chapey, R. (2001). Language Intervention Strategies in Aphasia and Related Neurogenic Communication Disorders. (4th ed.). Philadelphia, PA: Lippincott Williams \& Wilkins.

Chung, S. S. \& Joung, K. H. (2010). Predictors of health-related quality of life (HRQoL) in the home-dwelling disabled persons by using EQ-5D: Results from the 3rd Korea National Health and Nutritional Examination Survey 2005. Journal of Korean Academy of Adult Nursing, 22(3), 291-302.

Cohen, J. (1992). A power primer. Psychological Bulletin, 112(1), 155-159.

Cohen, J., Cohen, P., West, S. G., \& Aiken, L. S. (2013). Applied Multiple Regression/Correlation Analysis for the Behavioral Sciences. (3rd ed.). Mahwah, NJ: Routledge.

Cruice, M., Worrall, L., Hickson, L., \& Murison, R. (2003). Finding a focus for quality of life with aphasia: Social and emotional health, and psychological well-being. Aphasiology, 17(4), 333-353.

Dickson, S., Barbour, R. S., Brady, M., Clark, A. M., \& Paton, G. (2008). Patients' experiences of disruptions associated with post-stroke dysarthria. International Journal of Language and Communication Disorders, 43(2), 135-153.

Edelen, M. O., Stucky, B. D., Sherbourne, C., Eberhart, N., \& Lara, M. (2014). Correspondence between the RAND-negative impact of asthma on quality of life item bank and the Marks Asthma Quality of Life Questionnaire. Clinical therapeutics, 36(5), 680-688.

Erber, N. P. \& Scherer, S. C. (1999). Sensory loss and communication difficulties in the elderly. Australasian Journal on Ageing, 18(1), 4-9.

Flowers, H. L., Silver, F. L., Fang, J., Rochon, E., \& Martino, R. (2013). The incidence, co-occurrence, and predictors of dysphagia, dysarthria, and aphasia after first-ever acute ischemic stroke. Journal of Communication Disorders, 46(3), 238-248.

Heine, C. \& Browning, C. J. (2002). Communication and psychosocial consequences of sensory loss in older adults: Overview and rehabilitation directions. Disability and Rehabilitation, 24(15), 763-773.

Hilari, K., Needle, J. J., \& Harrison, K. L. (2012). What are the important factors in health-related quality of life for people with aphasia? A systematic review. Archives of Physical Medicine and Rehabilitation, 93(1 Suppl), S86-S95.

Hilari, K. \& Northcott, S. (2006). Social support in people with chronic aphasia. Aphasiology, 20(1), 17-36.

Hilari, K., Wiggins, R., Roy, P., Byng, S., \& Smith, S. (2003). Predictors of health-related quality of life (HRQL) in people with chronic aphasia. Aphasiology, 17(4), 365-381.

Joe, S., Lee, I., \& Park, B. (2016). Factors influencing health-related quality of life of young adults and elderly with multimorbiditiy: A secondary analysis of the 2013 Korea health panel data. Journal of Korean Academy of Community Health Nursing, 27(4), 358-369.

Kim, H. H. (2012). Neurogenic Speech-Language Disorders. Seoul: Sigmapress.

Kim, H. H., Kim, J. W., Heo, J. H., Kim, D. Y., \& Sung, S. J. (2008). Content validity of aphasia screening test protocol. Communication Sciences and Disorders, 13(3), 353-380.

Kim, K. B., Lee, Y. J., \& Sok, S. H. (2008). A comparative study on health status, depression, and quality of life between the elderly living with family and the elderly living alone. Journal of Korean Academy of Adult Nursing, 20(5), 765-777.

Kim, K. H. (2016). The factors influencing to quality of life of middle-aged women. Journal of the Korean Data Analysis Society, 18(1), 497-508.

Kim, K. J., Heo, M., Chun, I. A., Jun, H. J., Lee, J. S., Jegal, H., et al. (2015). The relationship between stroke and quality of life in Korean adults: Based on the 2010 Korean community health survey. Journal of Physical Therapy Science, 27(1), 309-312.

Kim, M. K., Tak, Y. J., Kang, G. W., \& Hong, J. Y. (2017). Related factors of individual and community levels affecting health-related quality of life. 
Journal of the Korean Data Analysis Society, 19(2), 1025-1037.

Kim, S. J., Shin, J. C., Kim, D. Y., \& Kim, H. H. (2012). Korean version of stroke and aphasia quality of life scale-39 (K-SAQOL-39): Its validity and reliability. Journal of Rehabilitation Research, 16(4), 245-265.

Kim, Y. H. (2009). A study on the related of daily life activity and the health related quality of life between the elderly at home and at institution. Journal of The Korean Data Analysis Society, 11(3), 1273-1287.

Korea Centers for Disease Control and Prevention. (2010). Community Health Survey. Korea Centers for Disease Control and Prevention. Retrieved from https://chs.cdc.go.kr/chs/index.do.

Korea Centers for Disease Control and Prevention. (2012). Community Health Survey. Korea Centers for Disease Control and Prevention. Retrieved from https://chs.cdc.go.kr/chs/index.do.

Lee, H. S. (2014). The factors influencing health-related quality of life in the elderly: Focused on the general characteristics, health habits, mental health, chronic diseases, and nutrient intake status: Data from the fifth Korea National Health and Nutrition Examination Survey (KNHANES V), 2010 2012. Korean Journal of Community Nutrition, 19(5), 479-489.

Lee, L., Chamberlain, L. G., Loudon, R. G., \& Stemple, J. C. (1988). Speech segment durations produced by healthy and asthmatic subjects. Journal of Speech and Hearing Disorders, 53(2), 186-193.
Lee, M. S. (2004). Factors influencing life satisfaction the elderly living alone. Journal of Korean Academy of Adult Nursing, 16(1), 17-26.

Manders, E., Dammekens, E., Leemans, I., \& Michiels, K. (2010). Evaluation of quality of life in people with aphasia using a Dutch version of the SAQOL-39. Disability and Rehabilitation, 32(3), 173-182.

Nam, H. S., Kim, K. Y., Kwon, S. S., Koh, K. W., \& Poul, K. (2007). EQ-5D Korean Valuation Study Using Time Trade Off Method. Seoul: Korea Centers for Disease Control and Prevention.

Park, M. H. \& Yim, S. Y. (2014). Relationship between dietary behaviors, health behaviors, and depression among the middle and high school students in Korea. Journal of the Korean Data Analysis Society, 16(5), 2683-2694.

Ross, K. \& Wertz, R. (2003). Quality of life with and without aphasia. Aphasiology, 17(4), 355-364.

Ross, K. B. \& Wertz, R. T. (2002). Relationships between language-based disability and quality of life in chronically aphasic adults. Aphasiology, 16(8), 791-800.

Walshe, M. \& Miller, N. (2011). Living with acquired dysarthria: The speaker's perspective. Disability and Rehabilitation, 33(3), 195-203.

Williams, L. S., Weinberger, M., Harris, L. E., Clark, D. O., \& Biller, J. (1999). Development of a stroke-specific quality of life scale. Stroke, 30(7), 1362-1369. 